\title{
The Formation of Carbon Monoxide from Diffusion Flames
}

\author{
S. LOMAX and R. F. SIMMONS \\ Department of Chemistry \\ The University of Manchester Institute of Science and Technology \\ Manchester M60 10D, England
}

\section{ABSTRACT}

The conditions have been determined under which propane diffusion flames burning around sintered metal hemispheres in an atmosphere of air and nitrogen give a high concentration of carbon monoxide in the exhaust gases. Concentration profiles have also been obtained through representative flames and across the burner housing above the burner. The results show that when the flame burns with a deficiency of oxygen, the central core of the products contains a high concentration of propane as well as propylene, ethylene, acetylene and methane. In addition, just above the top of the burner, the oxygen concentration has fallen to almost zero, and even well away from the burner it is only a tenth of its original level. It is clear that pyrolysis reactions and secondary oxidation processes occur in the region above the burner and that it is these processes which are responsible for the increased formation of carbon monoxide which occurs with flames burning in a deficiency of oxygen.

\section{INTRODUCTION}

There has been much concern about the level of toxic gases in the vicinity of a fire, and a particular example is the formation of carbon monoxide (Co). The relative levels of $\mathrm{CO}$ and carbon dioxide $\left(\mathrm{GO}_{2}\right)$ have been determined in the combustion products from a model fire burning in a compartment [1], and the experimental conditions simulated the typical dimensions of a living room, its contents and the degree of ventilation likely to be encountered in a real fire. The formation of CO was favoured by vitiated conditions in the compartment, and up to $15 \%$ of the total oxides of carbon was $c 0$.

This type of fire involves a diffusion flame and there are two basic mechanisms which can be envisaged by which the formation of co can be enhanced in such flames. When a diffusion flame burns in a vitiated atmosphere the maximum temperature in the reaction zone is relatively low and the flame consists of a thin blue luminous region [2]. As a result, there is the possibility that co can escape through the reaction zone into the surrounding atmosphere without being converted to $\mathrm{CO}_{2}$. The other possibility is that the hot combustion products from the flame still contain unburnt fuel, or more likely the products of its pyrolysis, and that these react subsequently with residual oxygen when mixing with the surrounding atmosphere occurs.

The present work was undertaken to examine the relative importance of 
these two mechanisms. Sintered hemispherical burners were used to determine the experimental conditions under which a laboratory scale diffusion flame gives a high overall [CO] in the combustion products when propane is the fuel, and concentration profiles have been determined through diffusion flames burning on cylindrical burners and through the combustion products at two heights above the burner.

\section{EXPERIMENTAL}

\section{Measurement of Overall Concentrations}

The hemispherical burners (see Fig. 1) were made by cold pressing stainless steel powder directly onto a threaded backplate [3]. The required flow of propane and nitrogen was fed through the backplate by a $6 \mathrm{~mm} 0 . \bar{d}$. stainless steel tube which was water-cooled and a small cup was situated $3.5 \mathrm{~cm}$ above the burner to collect any water that condensed on the cooling jacket. The top of this cooling jacket was sealed into a water-cooled cone which was slightly smaller than a B45 glass joint. Two grooves were cut into the wall of this cone and Viton 0-rings located in these grooves ensured a gas-tight seal when the burner was positioned in the burner housing [4].

The sintered hemisphere was situated about $5 \mathrm{~cm}$ below the rim of a 7.5 $\mathrm{cm}$ diameter Pyrex tube (94 cm long) which, in turn, was sealed axially inside the burner housing (10 cm diameter x $110 \mathrm{~cm}$ high) to give a chamber $30 \mathrm{~cm}$ high above the rim of the inner tube. The required flow of oxygen and nitrogen was fed up this inner tube, and a flow of nitrogen was fed up the annular jacket to minimise any recirculation of combustion products in the upper part of the burner housing. This arrangement gave a very stable counterflow diffusion flame and the dimensions of the apparatus ensured that all gas flows were laminar.

The combined gas flows passed out of the housing through a $26 \mathrm{~mm}$ i.d. tube, $4 \mathrm{~cm}$ from the top of the housing, and the major part of the water was removed by passage through two water-cooled condensers. Part of the flow was also passed through two traps cooled to $-80{ }^{\circ} \mathrm{C}$, to remove the final traces of water vapour, and thence to a Pye 104 gas chromatograph, where Go was determined using a $2.5 \mathrm{~m}$ column of Molecular Sieve $5 \mathrm{~A}$ and $\mathrm{CO}_{2}$ using a $1.5 \mathrm{~m}$ column of Poropak Q. AlI quantitative measurements were made using peak areas from a Hewlett-Packard 3352 integrator and data system in conjunction with calibrations obtained by injecting samples of known composition. In a typical
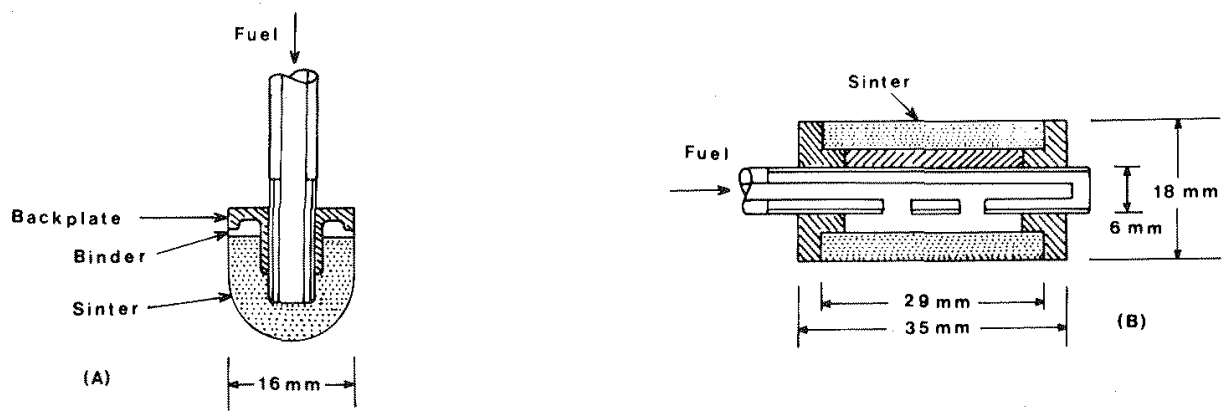

FIGURE 1. Details of burner construction.

(A) hemispherical burner, (B) cylindrical burner. 
set of measurements the interval between determinations was about 30 minutes, which corresponded to at least 10 volume changes for the whole system, and thus a steady state always existed throughout the system when measurements were made.

The equivalence ratio through a diffusion flame varies from fuel rich to lean, but the overall experimental conditions for a given flame can be defined in terms of the overall stoichiometry ( $\phi)$, which is given by the oxygen flow required for stoichiometric combustion of the fuel divided by the actual oxygen flow. Thus a value of $\phi=2.0$ implies that the oxygen flow was only half that required for stoichiometric combustion.

\section{Concentration Profiles}

In this part of the work, the burner was a hollow sintered cylinder [5], whose ends were sealed with stainless steel plates which were locked into position with a threaded pipe which passed through the centre of the cylinder (see Fig. 1). This pipe also served as the fuel inlet pipe and the upper part of the annular space was blocked off to restrict fuel flow to the bottom half of the cylindrical surface. This arrangement gave a flame which was parallel to and at a unform distance from the burner surface, so that the lateral positioning of the probe was less critical than with a hemispherical burner. The probe was made from $6 \mathrm{~mm} 0 . \mathrm{d}$. quartz tubing; the orifice was $\approx 70 \mu \mathrm{m}$, with an external diameter at the tip of $w 1 \mathrm{~mm}$, and the angle subtended at the tip was $15^{\circ}$. A VG $Q 8$ quadrupole mass spectrometer was used for the analyses; a background pressure of $10^{-9}$ Torr was routinely obtained in the mass spectrometer and the sample pressure was normally about $10^{-8}$ Torr.

The cracking patterns were determined for each of the species $\mathrm{Ar}, \mathrm{O}_{2}, \mathrm{CO}$, $\mathrm{CO}_{2}, \mathrm{C}_{3} \mathrm{H}_{8}, \mathrm{C}_{3} \mathrm{H}_{6}, \mathrm{CH}_{4}, \mathrm{C}_{2} \mathrm{H}_{4}, \mathrm{C}_{2} \mathrm{H}_{2}$, and $\mathrm{H}_{2} \mathrm{O}$, together with their sensitivities (rélative to argon). These enabled the mass spectral data to be converted to

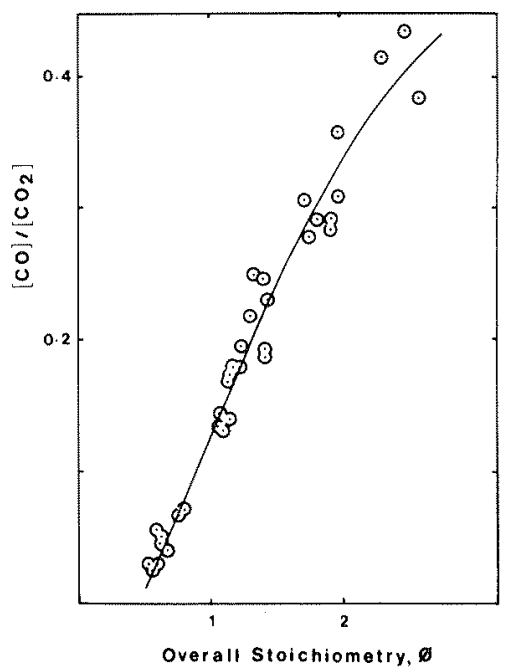

FIGURE 2. Variation of $[\mathrm{CO}] /\left[\mathrm{CO}_{2}\right]$ in the exhaust stream with overall stoichiometry. 
composition profiles [5]; the peaks at m/e $=20(\mathrm{Ar}), 32\left(\mathrm{O}_{2}\right), 29\left(\mathrm{C}_{3} \mathrm{H}_{8}\right), 44\left(\mathrm{CO}_{2}\right)$, $39\left(\mathrm{C}_{3} \mathrm{H}_{6}\right), 25\left(\mathrm{C}_{2} \mathrm{H}_{2}\right), 27\left(\mathrm{C}_{2} \mathrm{H}_{4}\right), 28(\mathrm{CO}), 15\left(\mathrm{CH}_{4}\right)$ and $18\left(\mathrm{H}_{2} 0\right)$ were used for the individual species after subtracting contributions from any other species to that peak. Argon was used as diluent to avoid the problem of identifying $C O$ in the presence of $\mathrm{N}_{2}$.

\section{RESULTS}

Overall Concentrations

For the initial set of determinations, the air flow was kept constant and $\phi$ varied by altering the flow of propane to the burner. In addition, to avoid any possible complication from carbon formation in the flame, nitrogen was added to the air to eliminate the carbon zone, and the proportion of this nitrogen was kept constant. This gave a flame which consisted of a single blue reaction zone, and flames were burned for $0.55<\phi<2.55$. The results in Fig. 2 show that as $\phi$ increased from $0.55-1.5$ the ratio $[\mathrm{CO}] /\left[\mathrm{CO}_{2}\right]$ increased linearly. At this point, the co accounted for about $17 \%$ of the total oxides of carbon, but increasing $\phi$ above 1.5 only produced a modest increase in c0 formation. For a given value of $\phi$ the actual gas velocities of the oxidant and fuel streams had a negligible effect on $c 0$ formation, but increasing the oxygen content of the oxidant flow from $16-21 \%$ for $\phi=2.0$ produced a $30 \%$ increase in the $[\mathrm{CO}] /\left[\mathrm{CO}_{2}\right]$ ratio. In contrast, when $\phi<1.0$ the formation of of $\mathrm{CO}$ was not affected by the oxygen content of the oxidant stream.

The gas chromatographic results also enabled the residual oxygen in the exhaust stream to be determined and some typical results are shown in fig. 3. With $\phi<0.65$, the residual oxygen was that expected on the basis of stoichiometric combustion of the fuel, but even with $\phi=0.8$, i.e an overall $25 \%$ excess of oxygen, the experimental curve had begun to deviate from the theoretical line. It is particularly striking that for $\phi>1.5$ about $10 \%$ of the

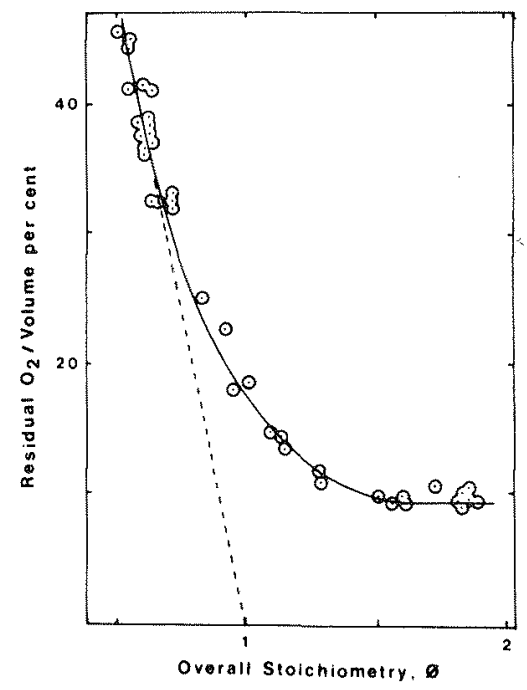

FIGURE 3. Variation of the residual oxygen in the exhaust stream with overall stoichiometry. 
original oxygen remained.

To obtain further information about the overall conversion of the propane to $\mathrm{CO}$ and $\mathrm{CO}_{2}$, the carbon balance was determined for a series of flames. This was done by adding a trace of neon to either the nitrogen flowing up the outer jacket of the burner housing or to the fuel itself, so that the ratio of the inlet flows of propane and neon gave the expected total flow of $\mathrm{CO}$ and $\mathrm{CO}_{2}$ relative to neon in the exhaust gas if all the carbon was converted to oxides of carbon. Comparison with the experimental results (including unburnt propane) then gave the carbon balance. In practice, identical results were obtained from the two ways and when there was an excess of oxygen the carbon balance was close to unity. In contrast, for $\phi>1.5$, about $35 \%$ of the initial propane was not accounted for. It is also striking that for these overall rich conditions about $10 \%$ of the carbon was still present as propane. There were also a few small peaks in the gas chromatograph which could not be identified with certainty, but these could not have accounted for the discrepancy. The most likely explanation for the missing carbon is the formation of formaldehyde which was present in the water condensed out from the exhaust stream, although this was not determined quantitatively.

\section{Concentration Profiles}

Figures 4 and 5 show the concentration profiles along a line at right angles to the midpoint of the burner surface for a flame with $\phi=2.0$. The start of the profile corresponds to the position at which the tip of the probe was just touching the burner surface, namely $0.5 \mathrm{~mm}$ from the surface. It will be seen that the $\left[\mathrm{C}_{3} \mathrm{H}_{8}\right]$ falls rapidly to zero at about $4 \mathrm{~mm}$, at which point the $\left[\mathrm{O}_{2}\right]$ begins to rise, reaching a steady value at $d=15 \mathrm{~mm}$. The $\left[\mathrm{O}_{2}\right]$ found experimentally at this point was that expected from the known input flows of

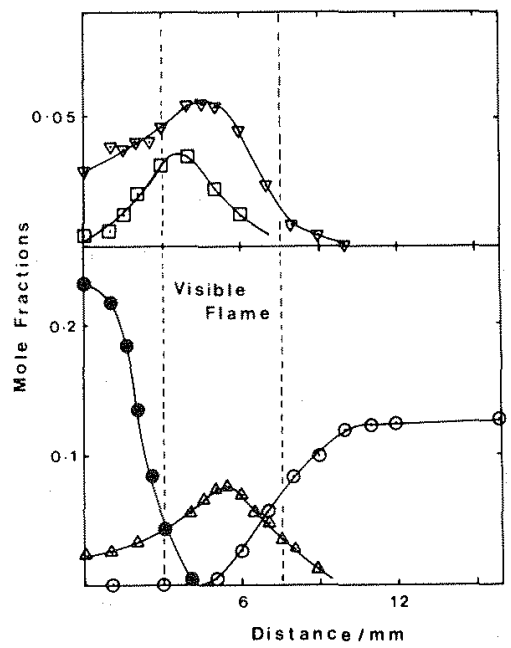

FIGURE 4. Concentration profiles for the major species through a propane diffusion flame $(\phi=2.0) . \quad \mathrm{C}_{3} \mathrm{H}_{8} ; \odot \mathrm{O}_{2} ; \Delta \mathrm{H}_{2} \mathrm{O} ; \quad \mathrm{CO} ; \nabla \mathrm{CO}_{2}$.

Input flows to: Burner: $400 \mathrm{~cm}^{3} \min ^{-1} \mathrm{C}_{3} \mathrm{H}_{8}+1020 \mathrm{~cm}^{3} \mathrm{~min}^{-1} \mathrm{Ar}$.
Jacket: $1000 \mathrm{~cm}^{3} \min ^{-13} \mathrm{~m}_{2}+7480 \mathrm{~cm}^{3} \mathrm{~min}^{-1} \mathrm{Ar}$. 


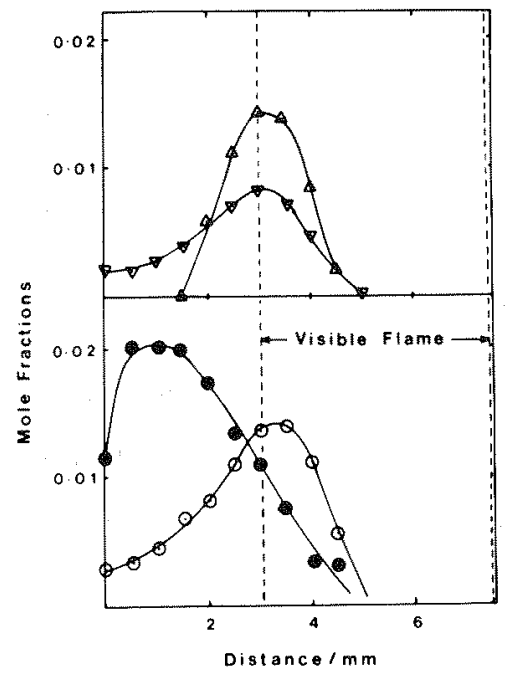

FIGURE 5. Composition profiles for the minor species through a propane diffusion flame $(\phi=2.0)$. Input flows as for Fig. 4 .

$\mathrm{C}_{3} \mathrm{H}_{6} ; \Delta \mathrm{C}_{2} \mathrm{H}_{4} ; \odot \mathrm{C}_{2} \mathrm{H}_{2} ; \nabla \mathrm{CH}_{4}$.

oxygen and argon to the jacket. In contrast, the $\left[\mathrm{C}_{3} \mathrm{H}_{8}\right]$ found at the burner surface was nearly 20\% Iower than expected from the input flows and this must arise from the forward diffusion of $\mathrm{C}_{3} \mathrm{H}_{8}$ into the flame as a result of the very steep concentration gradient for $\mathrm{C}_{3} \mathrm{H}_{8}$ between the burner surface and $\mathrm{d}=4 \mathrm{~mm}$. The profiles for $\mathrm{CO}, \mathrm{CO}_{2}$ and $\mathrm{H}_{2} \mathrm{O}$ have the expected shapes, reaching their maxima at $3.8,4.8$ and $5.4 \mathrm{~mm}$ respectively. Figure 5 shows the profiles for the minor species; $\mathrm{C}_{3} \mathrm{H}_{6}$ is formed very close to the burner surface, while $\mathrm{C}_{2} \mathrm{H}_{4}$, $\mathrm{C}_{2} \mathrm{H}_{2}$ and $\mathrm{CH}_{4}$ all reach their maximum at the inner edge of the flame.

The profiles through the other flames, which had values of $\phi$ ranging from 0.7 to 2.0, showed essentially the same spatial separation and maximum concentrations for $\mathrm{CO}_{2}$ and $\mathrm{H}_{2} \mathrm{O}$. As $\phi$ decreased, however, the maximum concentrations for $\mathrm{CO}$ and the intermediate hydrocarbons decreased. For example, with $\phi=1.0$ the maximum concentrations of $\mathrm{C}_{2} \mathrm{H}_{4}, \mathrm{C}_{2} \mathrm{H}_{2}$, and $\mathrm{CH}_{4}$ were about a factor of two lower, while the maximum for $\mathrm{C}_{3} \mathrm{H}_{6}$ was only about a quarter of its value in the flame with $\phi=2.0$. Comparison of the [Co] immediately outside the visible region of the flame showed that $C 0$ persisted further out when there was a deficiency of oxygen, but the actual [CO] in this region was not markedly affected by the value of $\phi$. As a result, it seems most improbable that the high CO levels obtained when the flame burned in a deficiency of oxygen could arise through the escape of $\mathrm{CO}$ through the flame into the surrounding atmosphere.

There was one major differnce in the appearance of the flames burning in a deficiency of oxygen from those with $\phi<1$. With the latter, there was a complete envelope of flame surrounding the cylinder, but the flames burning in a deficiency of oxygen had an open top. This difference is reflected in the concentration profiles higher up the burner housing. Figures 6 and 7 show the profiles for the flame with $\phi=2.0$ for a height of $4.8 \mathrm{~mm}$ above the top of the burner. In these profiles, the same zero position has been used as for the profiles through the flame, so that the position vertically above the midpoint of the top of the burner has a distance co-ordinate of $-9.5 \mathrm{~mm}$. Figure 6 shows 


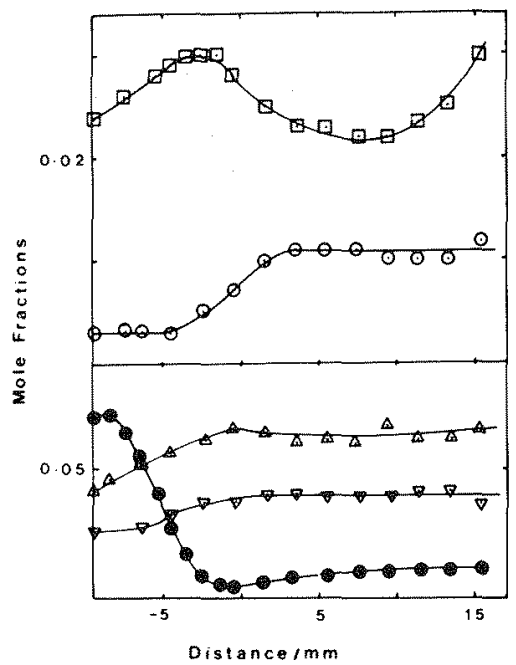

FIGURE 6. Composition profiles for the major species across the burner housing $4.8 \mathrm{~mm}$ above the burner $(\phi=2.0)$. Input flows as for Fig. 4 and 5 .

$\mathrm{C}_{3} \mathrm{H}_{8} ; \mathrm{O} \mathrm{O}_{2} ; \Delta \mathrm{H}_{2} \mathrm{O} ; 0 \mathrm{CO} ; \nabla \mathrm{CO}_{2}$.

that the steady oxygen level towards the housing wall has fallen to a tenth of its initial concentration, and it is even lower immediately above the burner. It is striking that the $\left[\mathrm{C}_{3} \mathrm{H}_{8}\right]$ immediately ebove the burner is still a third of its initial level (see Fig. 4). The profiles for $\mathrm{CO}_{2}$ and $\mathrm{H}_{2} \mathrm{O}$ are now

much flatter and their average concentrations are only slightly lower than the maximum concentrations found in the flame. The [CO] passes through a shallow maximum at $-3 \mathrm{~mm}$, and the average [Co] is significantly higher (relative to $\left[\mathrm{CO}_{2}\right]$ ) than in the flame. The most probable explanation of the increase in [CO] as the wall of the housing is approached is that some recirculation of combustion products occurs. Qualitative support for this view comes from the fact that although the flame itself had only a very weak carbon zone, a brown film of carbon was deposited on the housing wall and the probe tip became restricted by carbon after a period of use well outside the flame at this level.

Figure 7 shows that the profiles for $\mathrm{C}_{3} \mathrm{H}_{8}, \mathrm{C}_{2} \mathrm{H}_{4}, \mathrm{C}_{2} \mathrm{H}_{2}$ and $\mathrm{CH}_{4} 4.8 \mathrm{~mm}$ above the burner are also much broader than Iower down in the flame and, apart from $\mathrm{C}_{3} \mathrm{H}_{6}$ the concentrations are very similar to those in the flame. Thus the central core of combustion products contains a high concentration of these pyrolysis products. The concentrations of these species also have a tendency to rise as the housing wall is approached and this is a further indication that recirculation of combustion products is occurring.

The profiles $1 \mathrm{~cm}$ above the top of the burner for the same flame show an intermediate situation. The $\left[\mathrm{C}_{3} \mathrm{H}_{8}\right]$ above the burner is about half the value shown in Fig. 4 for near the burner surface, while the $\left[\mathrm{O}_{2}\right]$ well away from the flame has already fallen to the value found at $4.8 \mathrm{~cm}$ above the burner. The profiles for $\mathrm{CO}, \mathrm{CO}_{2}$ and $\mathrm{H}_{2} \mathrm{O}$ are already very much broader and significant levels of $\mathrm{C}_{2} \mathrm{H}_{4}, \mathrm{C}_{2} \mathrm{H}_{2}$ and $\mathrm{CH}_{4}$ are also present well away from the flame. 


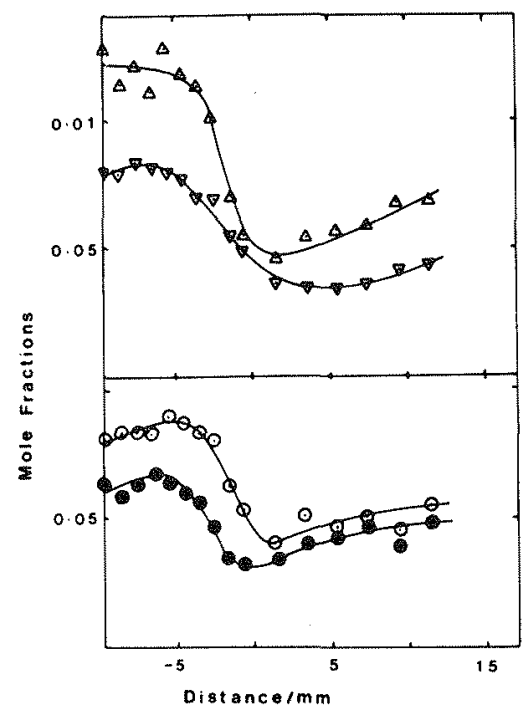

FIGURE 7. Composition profiles for the minor species across the burner housing $4.8 \mathrm{~mm}$ above the top of the burner $(\phi=2.0)$. Input flows as for Fig. 4 and 5. $\mathrm{C}_{3} \mathrm{H}_{6} ; \Delta \mathrm{G}_{2} \mathrm{H}_{4} ; \odot \mathrm{C}_{2} \mathrm{H}_{2} ; \nabla \mathrm{CH}_{4} \cdot$

\section{DISOUSSION}

The present results show that high concentrations of $C 0$ can be present in the exhaust stream from a diffusion flame burning in a vitiated atmosphere, and the levels observed are comparable to those obtained from model fires burning under similar conditions. It is clear that the ratio [CO]/[CO, in the exhaust stream is primarily controlled by the relative flows of fuel and oxygen, but the actual velocity of the oxidant stream or of the fuel from the burner surface has a negligible effect on the formation of $\mathrm{CO}$. In contrast, increasing the oxygen content of the oxidant flow actually increases co formation when there is an overall deficiency of oxygen. The primary reason for this behaviour can be seen from the composition profiles, which clearly show that when $\phi>1$ part of the fuel escapes upwards through the open top of the flame, and its subsequent reaction in the region above the burner results in the formation of more CO.

This possibility has been confirmed experimentally by adding trace amounts of $\mathrm{C}_{3} \mathrm{H}_{8}$ to the oxidant flow of a flame with $\phi=0.7$; Fig. 8 shows that this resulted in a marked increase in $\mathrm{CO}$ formation. Any $\mathrm{C}_{3} \mathrm{H}_{8}$ carried into the flame would have been converted to $\mathrm{CO}_{2}$, since there was an excess of $\mathrm{O}_{2}$ present, and thus the $C 0$ must have been formed when the hot combustion products from the flame mixed with the excess oxidant in the upper part of the burner housing. This would also explain the formation of formaldehyde; this is unlikely to survive the high temperature occurring in the flame, but it is a probable product of combustion at the lower temperature existing in the upper part of the burner housing.

The present paper only reports the results that are pertinent to the formation of $\mathrm{CO}$ and a more detailed report of the concentration measurements 


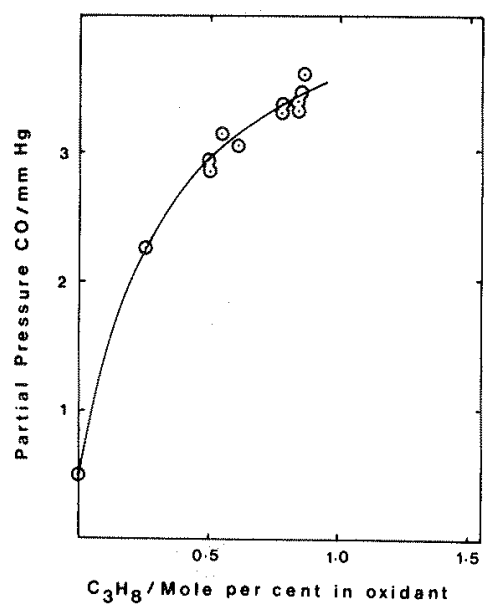

FIGURE 8. Effect on CO formation of adding $\mathrm{C}_{3} \mathrm{H}_{8}$ to the oxidant flow $(\phi=0.7)$.

and their mechanistic interpretation will be made elsewhere. Nevertheless, a brief discussion of the important reactions is appropriate. In the pyrolysis region of the flame (i.e. between the burner surface and the inner luminous edge of the flame), $\mathrm{C}_{3} \mathrm{H}_{6}, \mathrm{C}_{2} \mathrm{H}_{4}$, and $\mathrm{CH}_{4}$ were all detected and the following reactions represent the most plausible mechanism for their formation.

$\mathrm{X}+\mathrm{C}_{3} \mathrm{H}_{8}=\mathrm{FX}+\mathrm{C}_{3} \mathrm{H}_{7}$

$1-\mathrm{C}_{3} \mathrm{H}_{7}=\mathrm{H}+\mathrm{C}_{3} \mathrm{H}_{6}$

$\mathrm{n}-\mathrm{C}_{3} \mathrm{H}_{7}=\mathrm{CH}_{3}+\mathrm{C}_{2} \mathrm{H}_{4}$

$\mathrm{CH}_{3}+\mathrm{C}_{3} \mathrm{H}_{8}=\mathrm{CH}_{4}+\mathrm{C}_{3} \mathrm{H}_{7}$

In this scheme $X$ is any radical species which can abstract a hydrogen atom from $\mathrm{C}_{3} \mathrm{H}_{8}$. The most probable route for the formation of $\mathrm{C}_{2} \mathrm{H}_{2}$ is hydrogen abstraction from $\mathrm{C}_{2} \mathrm{H}_{4}$ and the subsequent pyrolysis of $\mathrm{C}_{2} \mathrm{H}_{3}$. The same basic mechanism can also account for the consumption of $\mathrm{C}_{3} \mathrm{H}_{8}$ which occurs above the burner.

The maximum in the profile for $c 0$ at $-3 \mathrm{~mm}$ and a height of $4.8 \mathrm{~mm}$ above the burner (see Fig. 6) clearly indicates that CO is still being formed in this region. In addition, although the profiles for $\mathrm{CO}_{2}, \mathrm{H}_{2} \mathrm{O}$ and $\mathrm{O}_{2}$ are quite flat moving out into the burner housing, their concentrations fall in the central core of the combustion products immediately above the burner. As the $\mathrm{O}_{2}$ level is already very low, it is unlikley that any direct reaction involving oxygen is a major route for the formation of $\mathrm{CO}$, but both $\mathrm{CO}_{2}$ and $\mathrm{H}_{2} \mathrm{O}$ could be involved in its formation. $\mathrm{CO}_{2}$ is diffusing back into a region which is fuel. rich and thus there is the possibility that some co is formed by the water gas equilibrium which will be maintained by reaction (5).

$\mathrm{CO}_{2}+\mathrm{H}=\mathrm{CO}+\mathrm{OH}$

Reaction (5) has an activation energy of $26.5 \mathrm{kcal}$ mol-1 [6] and thus it will not be a very fast process, but part of the co formation almost certainly arises from this route. The fall in the $\left[\mathrm{H}_{2} \mathrm{O}\right]$ in the central core of combustion 
products above the burner also indicates that it is being removed in this region. It is probable that the combustion products in this central core are in thermal and chemical equilbrium and hence the removal of oH by processes such as reaction (6) will not only remove $\mathrm{H}_{2} \mathrm{O}$ but also form $\mathrm{CO}$ through the intermediate formation of formaldehyde [7].

$$
\mathrm{OH}+\mathrm{C}_{2} \mathrm{H}_{4}=\mathrm{CH}_{3}+\mathrm{CH}_{2} \mathrm{O}
$$

There was no clear evidence, however, from the mass spectra that formaldehyde was present, but its major peaks (at $m / e=29$ and 28 ) coincide with those of other species. Thus a high concentration would need to be present before there was any significant effect on the ratio of the peaks at $\mathrm{m} / \mathrm{e}=29$ and 43; within experimental error, this ratio was always that expected for $\mathrm{C}_{3} \mathrm{H}_{8}$

The situation which exists when a real fire burns in a compartment will be different to that existing in the present work, but there are sufficient similarities to enable the present results to be applied to the real fire situation with confidence. In the present work the combustion products left the burner housing at the top, but even so, the composition profiles suggest that some recirculation of combustion products occurred near the wall of the housing. It is also clear from the results, that secondary reactions in the region above the burner is important, both from the point of view of pyrolysis of excess fuel and also for the formation of co. In the initial stages of a real fire burning in a room there will be a closed envelope of flame, but as the fire develops and grows, the plume of hot gases from the fire will reach the ceiling of the compartment and spread out sideways. At this stage, the fire is essentially an open topped diffusion flame, so that the central core of the plume of hot gaes from the fire will be comprised mainly of pyrolysis products. These can only leave the compartment through any openings that may be present, and these will also admit the air which sustains the fire. In a closed compartment, therefore, these hot products must mix with the atmosphere in the compartment by recirculation, and some recirculation will also take place even when there is a ventilation opening present. The same type of situation will then exist as in the present work from the point of view of the occurrence of secondary reactions. The details of the mixing processes will be different in the two cases, however, and in the compartment fire they are likely to be less reproducible, unless the experimental conditions are very carefully controlled. Nevertheless, the present work clearly shows that the high [Co] arises from secondary reactions which occur in the housing above the flame and essentially the same situation can occur when a fire burns in a confined space.

This paper forms part of the work of the Fire Research Station, Building Research Establishment, Department of the Environment. It is contributed by permission of the Director, Bullding Research Establishment.

\section{REFERENCES}

1. Raferty, M.M.: Building Research Establishment, Note N53/81.

2. Simmons, R.F. and Wolfhara, H.G.: Combustion \& Flame, 1, 155 (1957).

3. Lomax, S.: Ph.D. Thesis, University of Manchester, 1985.

4. Crowhurst, D. and Simmons, R.F.: Fire \& Materials, 7, 62 (1983).

5. Crowhurst, D. and Simmons, R.F.: Combustion Flame, 59, 167 (1985).

6. Westley,F.: "Table of Recommended Rate Constants for Chemical Reactions Occurring in Combustion," NSRDS-NBS 67 (1980).

7. Baldwin,R.R.and Walker R.W.: Eighteenth Symposium (International) on Combustion," p. 819, The Combustion Institute, Pittsburgh, 1981. 